\title{
Setting up a vasectomy service in Ireland
}

\author{
John Boyle
}

\section{What was my previous experience?}

I commenced work as a general practitioner (GP) in Ennis, County Clare, Ireland in December 2002. My previous experience of vasectomies was general anaesthetic procedures in a hospital-based GP service in Australia. Having moved to Ireland, I was keen to continue my procedural work in some way. I set up facilities for minor surgery and also carried out procedures such as insertion of intrauterine devices and the contraceptive implant (Implanon ${ }^{\circledR}$ ).

\section{Was there a need for the service?}

A colleague suggested that there was a need in the area for a GP to carry out vasectomies, however I certainly did not consider myself competent or adequately experienced to do so without further training. In the Republic of Ireland the vast majority of vasectomies are carried out by GPs. In 1989, just over 3000 vasectomies were performed, over $96 \%$ of these by GPs.

\section{How did I gain the necessary skills?}

I contacted several GPs in Ireland who already performed vasectomy procedures. They were all very helpful, but were unable to provide any formal vasectomy training. I then got in touch with the Faculty of Sexual and Reproductive Healthcare (FSRH) in the UK, which provided a list of principal trainers in local anaesthetic vasectomies.

I worked my way through the list but had no success, either because the training dates weren't convenient or the patient lists were too small to make a journey across to the UK worthwhile. I eventually contacted the Sandyford Initiative in Glasgow, which is a large, integrated sexual and reproductive health care service, with seven vasectomy lists a week.

The trainer at the Sandyford Initiative, Dr Kay McAllister, was keen to help out and asked me to come over for supervised vasectomies. After General Medical Council and medical defence union checks, I flew over to Glasgow for the first of three visits.

On my first visit I carried out 17 vasectomies. In addition to surgical technique I was taught counselling skills, patient selection, and how to deal with intraoperative complications including vasovagal attacks, bleeding, and so on. I was also taught about postoperative complications such as infection, haematomas and chronic pain. I became aware of the differences in doing vasectomies under general as opposed to local anaesthesia. I learned that it is important to communicate with the patient and try and put them at their ease.

Learning how to do a vasectomy is a very tactile process. The most important thing is to correctly identify the vas deferens, which is about the same thickness and texture as a cooked strand of spaghetti. The next most important thing, once you have identified the vas and secured it, is don't let it go! The technique taught to me was a traditional vasectomy. Skin incisions are made with a scalpel. The vas deferens is

\section{J Fam Plann Reprod Health Care 2010; 36(2): 101}

Parnell Medical Centre, Ennis, County Clare, Eire

John Boyle, MBChB, MRCGP, General Practitioner

Correspondence to: Dr John Boyle, Parnell Medical Centre,

Parnell Street, Ennis, County Clare, Eire.

E-mail: drjohnboyle@gmail.com mobilised and a $1 \mathrm{~cm}$ length is excised. Diathermy is applied to both ends with fascial interposition, and finally skin sutures are applied.

I was instructed about postoperative seminal analysis: how to manage persistent sperm, regimes for scanty and numerous sperm, and when to check for motility. I visited a laboratory in Ireland and observed seminal analysis.

After the procedure each patient is provided with a 'pack' that includes instructions for posting postoperative seminal samples at 20 and 24 weeks.

\section{How was the service established?}

On my return to Ireland I attempted to reproduce the Sandyford Initiative set-up as closely as possible. I obtained all the relevant instruments, as well as an identical hyfrecator and vasectomy forceps. This was only possible with the assistance of my GP colleagues.

Having undertaken three supervised sessions in Glasgow, I arranged a list of patients in the Ennis Clinic and Dr McAllister arranged to travel over to review our operative set-up. This was very helpful for a number of reasons. It was good for my confidence to have a more experienced doctor present at my first session. It was useful in terms of sorting out any teething problems with equipment and procedures. It was also beneficial for the nursing staff to be able to discuss postoperative sampling and paperwork with Dr McAllister.

Currently I receive referrals from local GPs. We usually operate on a Friday morning as this gives the patient time to take things easy over the weekend.

Unlike the clinic in Glasgow, there is the issue of cost for patients in Ireland. If a patient holds a current medical card then the procedure is free to them, and a set fee is paid to the doctor by the local health authority. In Ireland, only about $30 \%$ of the population holds a medical card; cards are given to those on a low income, patients aged over 70 years and certain other patients (e.g. those with severe medical conditions). The majority of men will therefore pay for the procedure. The main health providers - Vhi Healthcare, Vivas Health (now Aviva Health) and Quinn Healthcare (formally BUPA) - refuse to cover any of the costs. The cost varies between doctors but is usually in excess of $€ 400$ (£347).

\section{What difficulties were encountered?}

The main problem that we have encountered to date relates to post-vasectomy seminal analysis. In Glasgow the local laboratory was happy to accept posted samples, however the laboratories in Ireland are not. We are currently exploring various options but may have to use a private facility.

I think the whole process has been quite challenging in terms of the time and effort needed to locate a vasectomy trainer as well as several overseas trips. The costs involved have been quite significant: time off work, locum fees, airfares, hotel expenses, in addition to the cost of equipment and tuition fees.

However, overall, I have found it has been a worthwhile experience. I feel that I am offering a valuable service to the local population and my referrals from local GPs are increasing all the time. I have added an extra dimension to my clinical work, which I personally have found very rewarding.

Funding and competing interests Funding None identified.

Competing interests None identified. 